\title{
DIREITO FUNDAMENTAL À GARANTIA DE EMPREGO: UMA ANÁLISE SOBRE A AUSÊNCIA DE REGULAMENTAÇÃO DO DISPOSITIVO CONSTITUCIONAL QUE O ABRIGA
}

\section{FUNDAMENTAL RIGHT TO SECURITY OF EMPLOYMENT: AN ANALYSIS ON THE ABSENCE OF CONSTITUTIONAL REGULATION OF DEVICE}

\begin{abstract}
Aline Carneiro Magalhães ${ }^{1}$
Roberta Freitas Guerra ${ }^{2}$

Resumo O período de debates e votação da Constituição brasileira de 1988 foi marcado, de um lado, pela luta dos trabalhadores por melhores condições de trabalho e, de outro, pela resistência patronal aos avanços sociais. O resultado deste embate foi a previsão, em seu art. $7^{\circ}$, I, da garantia de emprego contra a dispensa imotivada, norma esta que, embora ainda carente de regulamentação, impediu a ratificação pelo Brasil da Convenção no 158 da OIT. Neste contexto, o presente artigo tem como objetivo analisar algumas questões sobre o direito à garantia de emprego através de uma análise doutrinária e normativa, concluindo pela importância da ampliação dos debates sobre o tema com vistas à efetividade.
\end{abstract}

Palavras-chave Direito fundamental à garantia de emprego; Regulamentação do artigo $7^{\circ}$, inciso I da Constituição brasileira de 1988; Convenção nº 158 da OIT.

Abstract The periodof debates andvotingoftheBrazilianConstitutionof 1988 wasmarked, ontheonehand, bytheworkers' struggle for betterworkingconditionsand, ontheotherhand, theemployerresistanceto social progress. The resultofthisclashwasthepredictionoftheemploymentguaranteeagainstunfairdismissal in hisarticle 7, I,which, although still lackingregulation,preventedtheinternalratificationof ILO Convention No. 158. In this context, this article aims to analyze some questions about the right to guaranteed employment through a doctrinal and normative analysis, concluding on the importance of deepening the debate on the subject with a view to effectiveness.

\footnotetext{
${ }^{1}$ Doutoranda em Direito pela Pontifícia Universidade Católica de Minas Gerais. Mestre em Direito pela Pontifícia Universidade Católica de Minas Gerais - Linha de Pesquisa: Direito do Trabalho, Modernidade e Democracia (2013). Professora do Ensino Superior.

${ }^{2}$ Doutoranda em Direito do Trabalho pela Pontifícia Universidade Católica de Minas Gerais. Mestre em Direito do Trabalho pela Pontifícia Universidade Católica de Minas Gerais. Especialista em Direito do Trabalho e Processual do Trabalho pela Faculdade Estácio de Sá/MG. Professora Adjunta I do Departamento de Direito da Universidade Federal de Viçosa/MG.
} 
Keywords Fundamental righttoguaranteeemployment; Regulationofarticle7, I oftheBrazilianConstitutionof 1988; ILO Convention No. 158.

\section{INTRODUÇÃO}

Da emergência e desenvolvimento da sociedade industrial, aliados à existência de trabalho livre e assalariado, surgiu uma relação que interligava o homem ao sistema produtivo, denominada relação de emprego.

Junto com esta relação, a partir, de um lado, das reivindicações dos trabalhadores, identificados paulatinamente como uma classe representada por sindicatos, que reclamavam por melhores condições de trabalho e, de outro, da conscientização dos empregadores da necessidade de ceder parcialmente às pressões e conceder melhorias mínimas de trabalho, sob pena de ver o sistema ruir, surge o Direito do Trabalho.

Este ramo específico do Direito foi estruturado a partir do princípio da proteção, sempre visando atenuar, no plano jurídico, a desigualdade fática inerente à relação entre empregado e empregador.

Com a Constituição do México de 1917, a Constituição de Weimar de 1919 e a criação da Organização Internacional do Trabalho (OIT) neste mesmo ano, o Direito do Trabalho passa por um processo de constitucionalização e internacionalização que lhe confere mais força.

Paralelamente, neste período, a industrialização no Brasil ainda era pontual e incipiente. Como o trabalho livre é um dos pressupostos para a existência e desenvolvimento da relação de emprego e, consequentemente, do Direito do Trabalho, e em nosso território esse requisito era algo recém conquistado, por meio da Lei Áurea de 1888, acabou sendo tardio o desenvolvimento das indústrias em solo nacional.

Nesta época, a legislação trabalhista pátria se caracterizava por manifestações esparsas e singelas, o que perdurou até a década de 1930 (DELGADO, 2009).

Por volta de 1935, com uma intensa atividade administrativa e legislativa do Estado autoritário e corporativista, mas sensível à questão social, o Direito do Trabalho entra na fase de institucionalização, sendo as normas trabalhistas agrupadas em um diploma único, a 
Consolidação das Leis do Trabalho (CLT), o que ocorreu em 1943.

Nas décadas subsequentes, o modelo juslaboral posto não é alterado de maneira significativa. Ele se manteve praticamente intocado de 1930 a 1945. Na fase democrática, que compreendeu os anos de 1945 a 1964, não houve modificações relevantes, tampouco, durante o regime militar implantado em 1964.

Após meados da década 1980, ele começou a sofrer seu mais substancial questionamento, sendo objeto de debates e votações constituintes a partir de 1987, que resultaram na Constituição da República de 1988(CR/88), marco de afirmação e valorização do Direito do Trabalho no país.

Este ramo especial do Direito, agora alçado ao patamar de direito fundamental constitucionalmente garantido, estava diante de uma nova fase, regido por normas que davam ênfase à melhoria da condição social do trabalhador.

É neste contexto que é redigido o texto do art. $7^{\circ}$, inciso I, da CR/88, que prevê a garantia de emprego contra dispensa arbitrária ou sem justa causa, na mesma linha protetiva da Convenção nº 158 da OIT, de 1982.

Entretanto, logo após a promulgação da CR/88, fortalece-se no país, em âmbito oficial e nos meios privados de opinião pública, um pensamento denominado neoliberal, disseminado mundialmente, baseado, dentre outras premissas, na desestruturação das normas trabalhistas taxadas de rígidas e prejudiciais ao desenvolvimento econômico.

Esse momento foi marcado pelo discurso patronal de cunho flexibilizatório e desregulamentador que persiste até os dias atuais.

Um dos maiores alvos de ataque da nova política neoliberal foi o direito à garantia de emprego, que passou por momentos de efetivação e negação.

Isto porque, de um lado, o art. $7^{\circ}$, I, da CR/88 estabelece que lei complementar posterior deve regulamentar seu dispositivo.

De outro lado, a Convenção $n^{\circ} 158$ da OIT, que trata do mesmo assunto, aprovada pelo Congresso Nacional em 16/09/92 e promulgada em 11/04/96, foi denunciada pelo Poder Executivo em 20/11/96, deixando de ter vigência em nosso ordenamento a partir de 20/11/97.

Muitos questionamentos foram feitos acerca da denúncia, em especial pela não observância do prazo e procedimentos corretos para sua realização. A insurgência chegou a ser realizada através da interposição de Ação Direta de Inconstitucionalidade (ADIn).

Em meio à falta de regulamentação do art. $7^{\circ}$, I, da CR/88 e da denúncia da Convenção $\mathrm{n}^{\circ} 158$ da CLT, continua o obreiro sujeito a dispensas imotivadas, que colocam 
fim a seu vínculo de emprego sem qualquer justificativa, não tendo ele mínimas garantias da continuidade da sua relação empregatícia.

A garantia de emprego contra a dispensa arbitrária ou sem justa causa acaba sendo uma promessa não cumprida, perdurando na prática laboral a facilidade jurídica conferida aos empregadores de dispensarem seus empregados.

Esta facilidade implica na imensa rotatividade de mão-de-obra, que, além de impulsionar o desemprego, favorece a insegurança nas relações trabalhistas, fragilizando a situação do trabalhador, em especial em um contexto de flexibilização, precarização e desregulamentação. A mesma rotatividade gera gastos consideráveis para as empresas, especificamente com recrutamento, treinamento e período de adaptação do novo funcionário.

A ausência de uma garantia no emprego gera, muitas vezes, a submissão do obreiro a condições de labor divorciadas do padrão mínimo estabelecido por lei, com jornadas extenuantes, baixa remuneração, exercício de atividade em ambientes em que não há o cumprimento de normas de saúde e segurança, ausência de intervalos, dentre outros problemas.

Nesta ordem de ideias passamos a analisar, no presente trabalho, o direito fundamental à garantia de emprego, partindo do estudo do Direito do Trabalho como direito fundamental capaz de promover o princípio da dignidade humana e gerar a melhoria das condições de vida dos obreiros, passando pela história do direito à garantia de emprego, pelos princípios da proteção e continuidade da relação de emprego, pela Convenção $n^{\circ} 158$ da OIT, pelo tratamento ao tema em outros ordenamentos jurídicos e por algumas repercussões no mundo do trabalho da regulamentação do art. $7^{\circ}$, I, da CR/88, sob o ponto de vista obreiro e patronal.

\section{O DIREITO DO TRABALHO COMO DIREITO HUMANO FUNDAMENTAL PROMOTOR DO PRINCÍPIO DA DIGNIDADE HUMANA E INSTRUMENTO DE MELHORIA DA CONDIÇÃO SOCIAL DO OBREIRO}

Em face das atrocidades cometidas contra o homem, em especial, decorrentes das grandes guerras, viu-se a necessidade de se reconhecer a dignidade humana como um valor e um princípio fundamental. 
Este valor foi consagrado na Declaração Universal dos Direitos Humanos de 1948, documento que reconheceu a dignidade humana como fundamento da liberdade, da justiça e da paz no mundo. No plano constitucional, a Alemanha, em 1949, foi a primeira a reconhecer a dignidade da pessoa como núcleo dos direitos fundamentais do cidadão (LEDUR, 1998).

A Constituição brasileira de 1998 deixou claro ser a dignidade humana o princípio e o fim maior de todo o ordenamento jurídico. No entanto, já em 1946, a Norma Fundamental fazia referência à dignidade, que, estava diretamente vinculada ao trabalho ${ }^{1}$. Segundo Ledur (1998, p.24), “a primeira forma de referência à dignidade humana em texto constitucional brasileiro ocorreu de forma associada ao trabalho".

Nesta ordem de ideias, mostra-se, a dignidade humana, como centro dos direitos humanos fundamentais, encontrando no trabalho um dos meios de sua efetivação.

Entretanto, não é qualquer trabalho que confere dignidade à pessoa, mas sim, aquele exercido nos moldes da legislação especial que tem por finalidade a melhoria das condições de vida e da pactuação da força de trabalho e a inserção socioeconômica de parte significativa da população que carece de riqueza material acumulada e que, por este motivo, vive do seu próprio trabalho ${ }^{2}$.

O Direito do Trabalho é o ramo do Direito que tem como objetivo central a promoção da dignidade do trabalhador, através de normas que possibilitem a melhoria da sua condição social e confiram um “patamar civilizatório mínimo”3. É ele também o responsável pela distribuição mais equânime dos proventos decorrentes dos avanços tecnológicos e do capitalismo.

O Direto do Trabalho permite que o labor exercido proporcione condições melhores de vida e desenvolvimento para o ser humano, promovendo a sua dignidade, sendo, assim, uma das maiores expressões dos Direitos Humanos Fundamentais.

Assim, os Direitos Humanos Fundamentais, o Princípio da Dignidade da Pessoa Humana, o Direito do Trabalho e o trabalho, mostram-se umbilicalmente interligados.

\footnotetext{
${ }^{1}$ Art. 145 da Constituição de 1946: “A ordem econômica deve ser organizada conforme os princípios da justiça social, conciliando a liberdade de iniciativa com a valorização do trabalho humano”. Parágrafo único: “A todos é assegurado trabalho que possibilite existência digna. O trabalho é obrigação social”.

2 Além desta função, Maurício Godinho Delgado (2009) assevera que o Direito do Trabalho tem caráter progressista, modernizante e político conservador.

${ }^{3}$ Expressão cunhada por Maurício Godinho Delgado (2009).
} 
A partir do momento em que o princípio da dignidade da pessoa humana se torna o eixo central dos Direitos Humanos, se mostra, o Direito do Trabalho, como um dos instrumentos mais adequados para promovê-lo ${ }^{4}$.

É por meio do trabalho prestado com respeito ao Direito do Trabalho que a maioria das pessoas, destituídas de riqueza, têm a oportunidade de, além de prover seu sustento próprio e o de sua família, melhorar a sua condição de vida.

É através dele que se pode prover uma educação e saúde de melhor qualidade, adquirir bens de consumo, ocupar um espaço socialmente reconhecido, realizar projetos e, consequentemente, desfrutar de um padrão de vida digno e humano.

O Direito do Trabalho humaniza o capitalismo e permite a inserção do indivíduo na sociedade mediante a partilha de ganhos decorrentes deste sistema. Segundo Maurício Godinho Delgado:

Esse padrão básico de dignidade social, econômica e profissional é, na sociedade capitalista, conferido, classicamente, à maioria das pessoas pelo Direito do Trabalho. A história do capitalismo ocidental demonstra que não se criou ainda neste sistema de desigualdade melhor padrão de inserção da grande massa dos indivíduos no mercado econômico senão por meio da norma justrabalhista, do Direito do Trabalho (DELGADO, 2004, p.375).

Complementa o autor dizendo que, por meio de um rol de normas tuitivas, é possível se fazer justiça social e distribuição de renda:

[...] é pela norma jurídica trabalhista, interventora no contrato de emprego, que a sociedade capitalista, estruturalmente desigual, consegue realizar certo padrão genérico de justiça social, distribuindo a um número significativo de indivíduos (os empregados), em alguma medida, ganhos do sistema econômico (DELGADO, 2004, p.122).

De acordo com Ledur (1998, p.167), “o direito a um posto de trabalho, com remuneração condigna, constitui condição sinequa non para que a imensa maioria dos indivíduos possa exercer o direito fundamental que está no princípio de todos, o direito à própria vida”, e, acrescente-se, um posto de trabalho onde haja a fruição de Direitos Trabalhistas, que cerque o trabalhador de garantias que lhe permita viver dignamente.

O mesmo autor assevera que “[...] somente na medida em que as pessoas puderem prover dignamente a seu sustento e ao de sua família, estarão aptas a influírem decisivamente na conformação do seu espaço vital” (LEDUR,1998, p.96), o que nos faz concluir que o

\footnotetext{
${ }^{4}$ Segundo Ledur (1998, p.149), “as mudanças econômicas vêm expondo à mais absoluta insegurança aqueles que necessitam de trabalho. Diante desse quadro, impõe-se ao Direito que sinalize quais as opções que o legislador e o administrador devem assumir para a afirmação dos direitos fundamentais sociais. Ou isso se dá com a garantia de proteção a quem precisa trabalhar para prover a sua existência, ou então o Direito será identificado com fórmulas vazias, como mero servo dos beneficiários da concentração da riqueza e poder”.
} 
exercício dos direitos fundamentais depende da existência de uma vida digna, que é alcançada por meio do trabalho resguardado pelo Direito Laboral. “A existência digna está intimamente relacionada ao princípio da valorização do trabalho humano. Assim, a dignidade da pessoa humana é inalcançável quando o trabalho humano não merecer a valorização adequada” (LEDUR, 1998, p.95), valorização esta que é alcançada por meio do cumprimento, aprimoramento e efetividade das normas trabalhistas.

Nesta ordem de ideias, aduz Maurício Godinho Delgado que:

O emprego, regulado e protegido por normas jurídicas, desponta, desse modo, como o principal veículo de inserção do trabalhador na arena socioeconômica capitalista, visando a propiciar-lhe um patamar consistente de afirmação individual, familiar, social, econômica e, até mesmo, ética (DELGADO, 2004, p.36).

A Declaração Universal dos Direitos Humanos, no art. 23, preceitua que "toda pessoa que trabalhe tem direito a uma remuneração justa e satisfatória, que lhe assegure, assim como à sua família, uma existência compatível com a dignidade humana”, e, esta remuneração é alcançada com a fruição dos direitos trabalhistas.

Segundo Ledur (1998, p.91) “o Direito é uma ciência normativa e social. Deve, em consequência, recolher na realidade normativa a fonte inspiradora para dar à dignidade da pessoa humana o conteúdo reclamado", assim, o Direito do Trabalho infere da realidade o importante papel que o trabalho exerce na sociedade e se ocupa de protegê-lo, promovendo a dignidade da pessoa humana e, por consequência, os direitos humanos ${ }^{5}$.

Analisando o passado, que não raro se repete no presente, podemos observar a superexploração, a miséria e a exclusão decorrente de um contexto em que parte dos atores sociais defendia a não incidência das normas trabalhistas.

A flexibilização, desregulamentação e primazia da autonomia da vontade entre partes desiguais geram deletérios efeitos na sociedade, pois, o trabalho e o Direito do Trabalho deixam de cumprir com o seu papel ${ }^{6}$.

\footnotetext{
${ }^{5} \mathrm{O}$ mesmo autor, com base na doutrina de Alexy, assevera que a dignidade não é garantida quando a pessoa é humilhada, discriminada, perseguida, desprezada ou encontra-se desempregada (LEDUR, 1998). A partir da ideia aqui defendida, pode-se acrescentar que também há ofensa à dignidade da pessoa humana quando os direitos trabalhistas não são cumpridos ou carecem de regulamentação. Importante salientar que é possível visualizar na seara laboral um baixo índice de cumprimento voluntário das normas trabalhistas, fato que pode ser atribuído a diversos fatores. Uma das formas de se alterar a realidade é através do Processo, pois, quanto mais célere e eficaz for a prestação jurisdicional, menos interessante será para o empregador deixar para pagar as verbas judicialmente. Neste contexto, as tutelas de urgência, evidência e metaindividual se mostram úteis a esta finalidade.

${ }^{6}$ Cumpre salientar que fora dos moldes do Direito do Trabalho, o poder aquisitivo dos trabalhadores e a arrecadação tributária diminuem o que é prejudicial ao próprio sistema. Maurício Godinho Delgado (2009) afirma que o Direito do Trabalho tem uma função política conservadora, na medida em que esse ramo jurídico especializado confere legitimidade política e cultural à relação de produção básica da sociedade contemporânea.
} 
Já dizia o pensador e religioso francês Lacordaire (apud VILLELA, 2013, p.8) no século XIX, que "entre o forte e o fraco, entre o rico e pobre, é a liberdade que escraviza, é a lei que liberta”. O Direito do Trabalho, nesta toada, é imprescindível para a existência de uma vida digna segundo os ditames dos Direitos Humanos Fundamentais.

Assim, a regulamentação dos direitos trabalhistas previstos na Constituição passa a ser uma máxima.

Assevera José Luiz Quadros de Magalhães (2000, p.15) que “muitas características da sociedade romana estão ainda presentes entre nós, mais notadamente, a existência de valores que colocam o patrimônio privado em escala valorativa maior do que a própria vida humana”.

Neste sentido pode-se observar uma retomada da prevalência do individualismo, materialismo e da busca incessante pelo lucro em detrimento das questões sociais, temática condizente com a discussão entre empregadores e empregados acerca da regulamentação do direito à garantia no emprego. As crises econômicas, o desemprego em massa e as pressões financeiras mundiais representam este contexto.

A efetividade e regulamentação dos direitos trabalhistas aparecem como uma alternativa para humanizar esse sistema, pois, como se buscou demonstrar, é o Direito do Trabalho que qualifica a relação empregatícia como um dos melhores instrumentos de realização da Dignidade da Pessoa Humana e de Direitos Humanos Fundamentais.

O caráter tuitivo do Direito do Trabalho, a sua capacidade de distribuir renda, sua feição de ação afirmativa e todos os benefícios decorrentes de um trabalho prestado sob o seu manto são capazes de gerar uma sociedade mais justa, humana e solidária.

Afinal, segundo nos coloca Comparato (2001, p.57), é necessário haver uma “consciência ética coletiva, a convicção, longa e largamente estabelecida na comunidade, de que a dignidade da condição humana exige o respeito a certos bens ou valores em qualquer circunstância”. Daí dever a dignidade humana do trabalhador, como valor elevado que é, ser respeitada e concretizada via Direito do Trabalho.

\section{O DIREITO À GARANTA DE EMPREGO SOB A PERSPECTIVA HISTÓRICA}

Logo no período inicial de criação do Direito do Trabalho no Brasil, época da incipiente industrialização no país, já existia a figura da garantia no emprego. 
Ela surgiu na esfera previdenciária e visava fixar o trabalhador no emprego como meio de financiamento das contribuições e benefícios da seguridade. De acordo com Andréa Vasconcellos, a estabilidade:

[...] inicialmente esteve relacionada às leis que regulamentavam as caixas de pensões e os institutos de previdência. Havia a necessidade de suprimento de fundos às instituições de previdência social, e a permanência no emprego proporcionava uma base segura para a continuidade das contribuições. De fato, dois elementos são de suma importância ao seguro social: o número de beneficiários e sua permanência na empresa (VASCONCELLOS, 2010, p.33).

A Lei Elói Chaves (Lei $n^{0}$ 4.682, de 1923), que criou a Caixa de Aposentadoria e Pensão dos Ferroviários, garantiu estabilidade aos empregados desta categoria após dez anos de permanência no serviço.

Em 1935, a estabilidade deixou de ligar-se à previdência, passando a constar na Lei $\mathrm{n}^{\circ} 62$, que tratava do contrato de trabalho.

As Constituições de 1937, 1946 e 1967 consagraram expressamente a estabilidade e, no mesmo sentido, a CLT, dos artigos 492 a 500, em harmonia com os princípios trabalhistas da proteção e da continuidade da relação de emprego. A norma jurídica valorizava a permanência do vínculo empregatício em face dos benefícios que gerava.

De acordo com a lei, o empregado que contasse com mais de dez anos de serviço na mesma empresa era considerado estável, podendo ser dispensado apenas por motivo de falta grave ou por circunstâncias de força maior devidamente comprovadas.

Antes de completados os dez anos, a dispensa imotivada se tornava mais onerosa proporcionalmente ao tempo de serviço, sendo devida ao obreiro uma indenização, calculada à base da maior remuneração do trabalhador por ano contratual ou fração igual ou superior a seis meses. “Ainda que fosse viável, juridicamente, o exercício potestativo da prerrogativa de rompimento unilateral do contrato (antes de dez anos ou nove, segundo a jurisprudência), tal exercício era, do ponto de vista econômico, fortemente restringido” (DELGADO, 2009, p.1138).

De acordo com a doutrina ${ }^{7}$, o sistema tradicional da estabilidade decenal ${ }^{8}$ promovia tanto a integração do trabalhador na empresa, quanto o princípio da continuidade da relação de emprego na medida em que restringia ou tornava economicamente desvantajoso o exercício do poder diretivo patronal para colocar fim ao contrato de trabalho.

\footnotetext{
${ }^{7}$ Por todos, Maurício Godinho Delgado (2009, p.1138).

${ }^{8}$ A terminologia decenal se devia ao tempo de 10 (dez) anos, após o qual os empregados alcançavam estabilidade no emprego.
} 
Entretanto, a norma em questão sempre fora objeto de muitas críticas, ao argumento de que era extremamente rígida e não contemplava, como fatores justificadores da dispensa, circunstâncias econômicas, financeiras e tecnológicas que, comprovadamente, afetassem a dinâmica e a estrutura empresarial.

Como resultado da insatisfação patronal, foi criado, em 1966, o sistema do Fundo de Garantia do Tempo de Serviço (FGTS). Nas palavras de Maurício Godinho Delgado:

\begin{abstract}
Tais críticas encontraram cenário político ideal para vicejarem no regime autoritário instaurado no país em 1964. Exponenciadas pelo discurso oficial do novo regime, harmônico a uma política econômica de franco cunho neoliberal, e pelo silêncio cirurgicamente imposto às vozes e forças adversas, essas críticas encontraram fórmula jurídica alternativa ao sistema celetista combatido - o mecanismo do Fundo de Garantia por Tempo de Serviço (DELGADO, 2009, p.1139).
\end{abstract}

O sistema do Fundo de Garantia surgiu para funcionar como um sistema alternativo ao da estabilidade decenal, cabendo ao trabalhador escolher a qual deles aderir no momento de celebração do contrato de trabalho.

Optando o trabalhador pelo sistema do Fundo de Garantia, teria, o mesmo, o direito a depósitos mensais em sua conta vinculada, no importe de 8\%(oito por cento) sobre o seu complexo salarial mensal e, quando da dispensa imotivada, a uma indenização no importe de 10\% (dez por cento)vdo montante total do FGTS depositado pelo seu empregador e corrigido monetariamente, além da possibilidade de sacar o valor constante na sua conta. Esta opção excluía o obreiro do sistema da estabilidade decenal e da indenização crescente proporcional ao tempo de serviço.

O modelo reduziu o obstáculo econômico à ruptura contratual, facilitando a dispensa imotivada, aproximando, neste aspecto, o mercado de trabalho brasileiro de um mercado do tipo liberal (DELGADO, 2009, p.1141).

Com a CR/88, colocou-se fim à dualidade de regimes, sendo universalizado o FGTS para todo o mercado de trabalho e revogada tacitamente a estabilidade decenal.

Entretanto, a mesma norma constitucional trouxe diretriz nova sobre a garantia de emprego, em verdadeira promoção ao trabalhador e aos princípios da dignidade da pessoa humana, valor social do trabalho, proteção e continuidade da relação de emprego. Para Maurício Godinho Delgado:

[...] a universalização do FGTS e revogação do antigo sistema estabilitário e de garantia do tempo de serviço da CLT poderiam fazer crer que a Carta Magna tivesse feito inequívoca opção política por um sistema do tipo liberal, isto é, um sistema não regulado, no tocante à dinâmica da continuidade e cessação dos contratos de trabalho no país. Esta conclusão não seria correta, entretanto, uma vez que a mesma 
Constituição trouxe [...] diretriz instigadora da busca de novo sistema de regulação das rupturas contratuais por ato empresarial (DELGADO, 2009, p.1141).

Tal diretriz está insculpida no texto do art. $7^{\circ}$, I, da CR/88, segundo o qual "são direitos dos trabalhadores urbanos e rurais, além de outros que visem à melhoria de sua condição social: I - relação de emprego protegida contra despedida arbitrária ou sem justa causa, nos termos de lei complementar, que preverá indenização compensatória, dentre outros direitos”.

Paralelamente, registre-se acerca da norma do art. 10, I, do Ato das Disposições Constitucionais Transitórias (ADCT) que, para compensar a ausência de regulamentação do citado art. $7^{\circ}$, I, da CR/88, majorou a multa do FGTS de 10\% (dez por cento) para 40\% (quarenta por cento) quando das dispensas imotivadas. Segundo o seu texto, “até que seja promulgada a lei complementar a que se refere o Art. $7^{\circ}$, I, da Constituição, fica limitada a proteção nele referida ao aumento, para quatro vezes, da porcentagem prevista no Art. $6^{\circ}$,caput e $\S 1^{\circ}$, da Lei $n^{\circ} 5.107$, de 13 de setembro de 1966 ”9.

Na mesma linha de proteção à manutenção do emprego, com o encarecimento da dispensa sem justa causa, a Constituição ainda criou, em seu inciso XXI, a figura do aviso prévio proporcional ao tempo de serviço, sendo este regulamentado em outubro de 2011, através da Lei $\mathrm{n}^{\circ} 12.506^{10}$.

Ao que nos parece, da análise dos textos dos dispositivos constitucionais citados, o Legislador Constituinte Originário buscou compatibilizar o direito à garantia de emprego com o direito ao FGTS, trazendo um novo enfoque à ótica estritamente individualista e antissocial, que defende a dispensa do empregado como direito potestativo empresarial, reafirmando, com isso, o primado conferido ao trabalho e o valor social deste enquanto instrumento de promoção da dignidade humana.

\section{OS PRINCÍPIOS DA PROTEÇÃO E DA CONTINUIDADE DA RELAÇÃO DE EMPREGO}

\footnotetext{
${ }^{9}$ Posteriormente, em 1990, a Lei $n^{\circ}$ 8.036, que substituiu a Lei $n^{\circ} 5.107$ e passou a dispor sobre o FGTS, incorporou, no texto de seu artigo 18, a disposição do artigo 10, inciso I, do ADCT. Resultado disso é o valor da multa agora devida ao empregado pela sua dispensa sem justa causa, no patamar de $40 \%$ (quarenta por cento) do montante de todos os depósitos realizados na conta vinculada durante a vigência do contrato de trabalho.

10 Art. 1": "O aviso prévio [...] será concedido na proporção de 30 (trinta) dias aos empregados que contem até 1 (um) ano de serviço na mesma empresa”. Parágrafo único: “Ao aviso prévio previsto neste artigo serão acrescidos 3 (três) dias por ano de serviço prestado na mesma empresa, até o máximo de 60 (sessenta) dias, perfazendo um total de até 90 (noventa) dias”.
} 
Dentre os diversos conceitos para o vocábulo princípio, pode o mesmo ser definido como aquilo que é tomado ou como ponto de partida e base sobre a qual se estrutura um conhecimento teórico e ou sobre que se constitui um sistema pragmático regulador de ações racionalmente voltadas para fins (MARÇAL, 2007). E complementa o autor dizendo que:

\begin{abstract}
Princípio, assim, denota uma relação de procedência ou de derivação entre elementos de uma totalidade ou sistema e é apresentado em uma formulação lingüística[sic] bem estruturada sintática, semântica e pragmaticamente. No âmbito do conhecimento teórico, o enunciado principiológico simultaneamente apresenta, correlaciona e integra, operacionalmente, elementos fundamentais do conhecimento em questão. No âmbito prático do agir, o enunciado principiológico se apresenta como um comando que regula ações e comportamentos (MARÇAL, 2007, p.87).
\end{abstract}

Sobre o tema, especificamente na seara laboral, assevera Américo Plá Rodriguez que:

[...] São enunciados básicos que contemplam, abrangem, compreendem uma série indefinida de situações. Um princípio é algo mais geral do que uma norma porque serve para inspirá-la, para entendê-la e para supri-la. E cumpre essa missão relativamente a número indeterminado de normas. Diz-se que constitui a base geral onde repousa o ordenamento, um sentido da legislação, uma orientação recorrente nela, que se reflete em uma pluralidade de disposições. Por isso se fala de princípios básicos ou fundamentais, porque servem de cimento a toda a estrutura jurídiconormativa laboral (PLÁ RODRIGUEZ, 2000, p.16).

O Direito do Trabalho nasce da existência de uma desigualdade entre os sujeitos da relação de emprego, o que justifica um ramo jurídico especializado para, no plano legal, tentar equilibrar a diferença social e econômica existente no plano fático entre empregado e empregador. Alice Monteiro de Barros, citando Salvatore Hernandez, aduz que o Direito do Trabalho:

[...] é um todo centralizado no princípio da tutela compensatória ao trabalhador subordinado, que consiste num conjunto de normas estabelecidas para contrabalançar a posição superior do empregador não apenas de fato, mas também juridicamente reconhecida e normativamente sustentada (HERNANDEZ apud BARROS, 2009, p.180).

O Direito do Trabalho é "um direito especial, que se distingue do direito comum, especialmente porque, enquanto o segundo supõe a igualdade das partes, o primeiro pressupõe uma situação de desigualdade que ele tende a corrigir com outras desigualdades” (DEVEALI apud SÜSSEKIND et al., 2005, p.144).

Este ramo do Direito se estrutura a partir de um núcleo basilar de princípios peculiares que têm por finalidade precípua a proteção do trabalhador, parte hipossuficiente da relação, para tentar minimizar a sua desigualdade frente ao empregador. 
Este conjunto fundamental é formado pelos princípios (i) da proteção; (ii) da continuidade da relação de emprego; (iii) da norma mais favorável; (iv) da irrenunciabilidade dos direitos; (v) da condição mais benéfica; (vi) da inalterabilidade contratual lesiva; (vii) da primazia da realidade e (viii) da imperatividade das normas trabalhistas.

Pode-se dizer que todos estes princípios decorrem do princípio da proteção e, para Alice Monteiro de Barros:

O princípio da proteção é consubstanciado na norma e na condição mais favorável, cujo fundamento se subsumeà essência do Direito do Trabalho. Seu propósito consiste em tentar corrigir desigualdades, criando uma superioridade jurídica em favor do empregado, diante da sua condição de hipossuficiente (BARROS, 2009, p.181).

Este princípio, segundo Gustavo Filipe Barbosa Garcia (2012) insere-se na estrutura do Direito do Trabalho como meio de minimizar a superexploração do capital sobre o trabalho e de promover melhorias nas condições de vida dos empregados. "O polo mais fraco da relação jurídica de emprego merece um tratamento jurídico superior, por meio de medidas protetoras, para que se alcance a efetiva igualdade substancial” (GARCIA, 2012, p.96).

Ao lado do princípio da proteção, é basilar do Direito do Trabalho também o princípio da continuidade da relação de emprego, segundo o qual, quanto mais tempo o obreiro mantiver um vínculo empregatício, mais benefícios ele alcançará, por meio do gozo das vantagens que o trabalho lhe proporciona. Nas palavras de Maurício Godinho Delgado:

[...] é de interesse do Direito do Trabalho a permanência do vínculo empregatício, com a integração do trabalhador na estrutura e dinâmica empresariais. Apenas mediante tal permanência e integração é que a ordem justrabalhista poderia cumprir satisfatoriamente o objetivo teleológico do Direito do Trabalho, de assegurar melhores condições, sob a ótica obreira, de pactuação e gerenciamento da força de trabalho em determinada sociedade (DELGADO, 2009, p.193).

Quanto maior tempo de vinculação do obreiro a seu empregador, mais condições ele tem de melhorar sua remuneração, de se qualificar e se afirmar socialmente. O empregador passa a ter mais interesse em investir nesse funcionário, que, por sua vez, busca aprimorar seus conhecimentos, gerando, assim, um círculo de vantagens.

Ademais, é por meio do trabalho, como citado, que a maioria das pessoas provê o sustento próprio e o de sua família, sendo importante estimular a manutenção do vínculo. Ademais,o trabalho é um meio de manutenção do próprio sistema capitalista, na medida em que o obreiro, com o uso de seu salário, consome os bens e serviços ofertados no mercado.

Este princípio é a base legal para a regra geral segundo a qual os contratos de emprego são firmados por prazo indeterminado e, apenas, excepcionalmente, a termo. 
Ele também é responsável por algumas presunções favoráveis ao obreiro, a exemplo da prevista na Súmula 212 do TST, que determinada que havendo a ruptura do vínculo presume-se que ocorreu da forma mais onerosa ao empregador (dispensa sem justa causa), cabendo a este, a prova de outra modalidade rescisória (pedido de demissão ou dispensa por justa causa). Ainda, dispõe a súmula que havendo controvérsia sobre a ruptura do vínculo, presume-se a continuidade do contrato.

O princípio da continuidade também é o fundamento para a sucessão de empregadores, prevista nos artigos 10 e 448 da CLT, que determinam que as alterações na estrutura da empresa não afetarão os contratos de trabalho, que permanecem vigentes e nas mesmas condições.

As estabilidades provisórias, a exemplo da estabilidade do dirigente sindical, da gestante, do cipeiro e do empregado acidentado, também são expressão deste princípio. E, "nas hipóteses de suspensão e interrupção ${ }^{11}$ do contrato de trabalho, embora não havendo a prestação de serviços, o contrato de trabalho não é encerrado, buscando-se, assim, a sua manutenção” (GARCIA, 2012, p.103).

Por tudo isto, o rol de princípios cardeais do Direito do Trabalho, dentre os quais se destacam os princípios da proteção e da continuidade da relação de emprego, representam o valor supremo deste ramo especial do Direito, devendo as demais normas serem criadas e interpretadas à sua luz.

Nesta ordem de ideias, emerge o direito à garantia de emprego, como expressão da concretização dos princípios da proteção e da continuidade da relação de emprego, pois, além de resguardar o obreiro do exercício potestativo da dispensa sem qualquer justificativa, ele permite a inserção do obreiro na estrutura empresarial por mais tempo, fato que gera benefícios não apenas para o trabalhador, mas também para o empregador, em especial, no que diz respeito à rotatividade de mão-de obra e aos gastos que dela decorrem.

\section{A CONVENÇÃO No 158 DA OIT: CONTEÚDO, DENÚNCIA E (IN)COMPATIBILIDADE COM O ART. $7^{\circ}$, I, DA CR/88}

\footnotetext{
${ }^{11}$ A suspensão e a interrupção do contrato de trabalho geram a cessação temporária da prestação de serviços pelo empregado. Mas, enquanto na suspensão não são devidos salários nem há cômputo do período de paralização no tempo de serviço do empregado (ex: intervalo inter e intrajornada), na interrupção há pagamento de salário e contagem do tempo de serviço (ex: período de férias, repouso semanal remunerado, faltas justificadas).
} 
Em 1982, foi editada a Convenção nº 158 da Organização Internacional do Trabalho, Pessoa Jurídica de Direito Público Internacional, criada em 1919 como parte do Tratado de Versalhes, que pôs fim à Primeira Guerra Mundial, fundada na convicção primordial de que a paz universal e permanente somente poderia estar baseada na justiça social.

Esta Convenção trata da proibição da dispensa arbitrária pelo empregador e elenca as hipóteses que não constituem motivos válidos de dispensa por justa causa ${ }^{12}$

Em 22 de junho de 1985, ela foi assinada e ratificada pelos dois primeiros países membros da OIT, sendo sua vigência internacional iniciada em 23 de novembro de 1985. "Hoje são 34 (trinta e quatro) países signatários, entre os quais estão incluídos: França, Portugal, Espanha, Suécia, Austrália, Finlândia, Turquia, Marrocos e Venezuela” (VASCONCELLOS, 2010, p.61).

A Convenção foi ratificada pelo Brasil em 5 de janeiro de 1995, entrando em vigência a partir de 5 de janeiro de 1996. Os Decretos Legislativo $n^{0}$ 68, de 1992 e Presidencial $n^{0} 1.855$, de 1996, respectivamente, a aprovaram e promulgaram.

De acordo com o art. $4^{\circ}$ da Convenção, “não se dará término à relação de trabalho de um trabalhador a menos que exista para isso uma causa justificada relacionada com sua capacidade ou seu comportamento ou baseada nas necessidades de funcionamento da empresa, estabelecimento ou serviço”.

Já segundo o disposto nos artigos $8^{\circ}$ e 10, o empregado é autorizado a recorrer perante um Órgão neutro, representado por um tribunal ou por um árbitro, caso tenha interesse em rever sua dispensa e analisar sua justificativa. Concluindo este Órgão ter sido injustificada a rescisão contratual, pode determinar ou a reintegração do obreiro ou o pagamento de uma indenização ou outra reparação adequada.

Conforme se infere do texto da Convenção, ela não proíbe a dispensa dos empregados; apenas a vincula a um motivo relevante, que pode ser ligado à conduta do obreiro ou a necessidades da empresa. Nas palavras de Maciel,

A Convenção 158, não é uma camisa de força, na qual a empresa se insere em
decorrência de uma norma proibitiva de seu direito potestativo de demitir. O que a
convenção 158 proíbe é a demissão arbitraria, mas admite que possa o empregado
ser demitido por causa justificada relacionada com sua capacidade, com seu
comportamento ou ainda, admite a demissão do empregado ou empregados desde

\footnotetext{
12 De acordo com o texto da Convenção, não constituem motivos válidos de dispensa por justa causa: filiação sindical; exercício de mandato de representação dos trabalhadores; apresentação de queixa ou participação em processos contra o empregador por violações da legislação; razões relacionadas a raça, cor, sexo, estado civil, responsabilidades familiares, gravidez, religião, opinião política, ascendência nacional ou origem social; ausência do trabalho durante licença-maternidade; e ausência temporária por força de enfermidade ou acidente.
} 
que comprovada a necessidade de funcionamento da empresa, estabelecimento ou serviço, o que evidencia a elasticidade da norma (MACIEL, 1996, p. 61).

Entretanto, apesar da elasticidade da dita norma internacional, a classe patronal colocou-se contrária à vedação da dispensa imotivada, tendo a ratificação da Convenção causado "reações exacerbadas da classe empresarial de todo o País, dado o suposto ônus econômico-financeiro que sua aplicação acarretaria aos empregadores” (VASCONCELLOS, 2010, p.75).

A classe patronal ainda buscou indispor o trabalhador em relação à Convenção $\mathrm{n}^{\circ}$ 158, afirmando, sem dados probatórios, que sua adoção acarretaria o fim da indenização de $40 \%$ (quarenta por cento) sobre o saldo do FGTS em caso de demissão justificada por motivos econômicos, tecnológicos, estruturais ou análogos por iniciativa do empregador ${ }^{13}$.

Neste contexto, a Confederação Nacional do Transporte e a Confederação Nacional da Indústria, em 08/07/1996, propuseram aADInn 1480/DF, com pedido de medida cautelar, questionando a validade jurídico-constitucional dos Decretos ratificadores da Convenção $\mathrm{n}^{\circ}$ 158 da OIT no Brasil, sustentando conflito com o art. $7^{\circ}$, I, da CR/88, que reserva à lei complementar a regulamentação do direito à garantia de emprego e que prevê indenização compensatória na hipótese de dispensa sem justa causa ${ }^{14}$.

Antes que o Judiciário apreciasse a ADIn, o Governo, por ato do Presidente Fernando Henrique Cardoso, em 20 de dezembro de 1996, denunciou a Convenção, mediante o Decreto $n^{\circ} 2.100$, afirmando que a sua manutenção:

[...] acarretaria visível desconforto aos Estados soberanos, vez que estaria sofrendo limitações no direito patronal de dispensar, no direito do trabalhador, as reparações advindas, além de fomentar intervenção estatal e reduzir o círculo de mobilidade dos interlocutores (VASCONCELLOS, 2010, p.74).

Após a denúncia da Convenção nº 158 da OIT por parte do Governo brasileiro,em 27/06/2001, o Relator da ADIn nº1480/DF, Ministro Celso de Mello, monocraticamente,

\footnotetext{
${ }^{13}$ Desconstruindo a afirmação da classe patronal, a Nota Técnica $n^{\circ}$ 61, de março de 2008, do Departamento Intersindical de Estatística e Estudos Socioeconômicos (DIEESE): “essa argumentação, contudo, não resiste a uma análise comparativa. O fato de o empregador brasileiro, pela atual legislação, poder demitir sem justa causa não o exime do pagamento da compensação de $40 \%$ do saldo do FGTS ao trabalhador. Em síntese, atualmente é legal demitir sem justa causa, mas tem que indenizar o trabalhador demitido. Do mesmo modo, uma futura regulamentação da garantia contra a dispensa imotivada pode prever situações em que é lícito demitir em algumas circunstâncias (motivos econômicos, tecnológicos, estruturais ou análogos bem definidos), desde que se pague ao trabalhador uma compensação pela perda do emprego. Se a compensação será menor, igual ou até mesmo maior do que a atual, só a lei complementar definirá” (DEPARTAMENTO, 2013).

${ }^{14}$ Por votação majoritária, em 4/09/1997, o Tribunal Pleno do STF decidiu o pedido de medida cautelar para, em interpretação conforme a Constituição, sem redução de texto, afastar qualquer exegese que viesse a ter como autoaplicáveis as normas da Convenção $\mathrm{n}^{0} 158$ da OIT, constituindo as mesmas meras propostas de legislação dirigidas ao legislador interno (restaram vencidos os Ministros Carlos Velloso, Ilmar Galvão, Marco Aurélio e Sepúlveda Pertence) (BRASIL, 2014b).
} 
julgou extinto o processo em virtude da perda superveniente de seu objeto, eis que também deixaram de existir os atos estatais - Decretos Legislativo $n^{\circ}$ 68/1992 e Presidencial $n^{\circ}$ 1855/1996 - questionados em sede de controle concentrado de constitucionalidade (BRASIL, 2014b).

Posteriormente, nova discussão foi travada, agora capitaneada pelos trabalhadores, impugnando a forma como ocorrera a denúncia da Convenção internacional.

Isto porque, de acordo com o art. 17 da referida Convenção, esta só poderia ser denunciada no fim de um período de 10 (dez) anos, a partir da data de sua entrada em vigor. Mas a dúvida girava em torno deste marco temporal, se seria a vigência no plano internacional (23/11/85) ou a vigência no plano interno (05/01/96).

Duas correntes se desenharam, então, a respeito da questão. Para uma primeira corrente, levando em consideração a vigência no plano internacional, a denúncia poderia ocorrer de 23/11/95 a 23/11/96. Como foi feita neste interregno - em 20/11/96 -, a mesma teria sido válida. Já para a segunda corrente, por dois argumentos, a denúncia da Convenção $n^{0} 158$ teria sido inválida. A um, porque realizada em menos de um ano após a vigência interna. A dois, porque, ainda que o marco temporal fosse a vigência internacional, a denúncia seria extemporânea, eis que seus efeitos se deram em 23 de dezembro de 1996 - após a publicação do Decreto $\mathrm{n}^{\circ} 2.100$, portanto -, quando deveriam ter se dado em 22 de dezembro de 1996, em razão mesmo da vigência internacional, ocorrida, como dissemos, em 23/11/1985 (VASCONCELLOS, 2010).

Alegando justamente que a denúncia feita pelo Presidente era eivada de vício, especificamente de inconstitucionalidade material, a Confederação Nacional dos Trabalhadores na Agricultura e a Central Única dos Trabalhadores, em 19/06/1997, ajuizaram a ADIn $n^{\circ}$ 1625/DF, que teve seu pedido julgado improcedente pelo Ministro Nelson Jobim, relator-presidente, em voto-vista, ao argumento, em suma, de que o chefe do Executivo "em razão de representar a União na ordem internacional, pode, por ato isolado e sem anuência do Congresso Nacional, denunciar tratados, convenções e atos internacionais” (VASCONCELLOS, 2010, p. 76) ${ }^{15}$.

Em meio a este imbróglio, em 20/02/2008, o então presidente da República, Luiz Inácio Lula da Silva, encaminhou mensagem aos membros do Congresso Nacional,

\footnotetext{
15 De acordo com o último andamento publicado no site do STF os autos da ADIn foram remetidos em 03/06/2009, ao Gabinete da então Ministra Ellen Gracie, em virtude de pedido de vista. Sem outra movimentação até 05/04/2011, quando Vanderlino Miranda Nunes requereu prioridade na tramitação do feito ainda pendente de julgamento (BRASIL, 2014c).
} 
solicitando a apreciação e incorporação ao nosso ordenamento jurídico dos termos da Convenção da OIT.

Na Câmara dos Deputados, a Mensagem no 59/2008 foi enviada, nesta ordem, à Comissão de Relações Exteriores e de Defesa Nacional ${ }^{16}$, à Comissão de Trabalho, deAdministração e Serviço Público ${ }^{17}$ e à Comissão de Constituição e Justiça e Cidadania.

Nas duas primeiras, no mérito, ela foi rejeita. Na última, em decorrência das rejeições anteriores, ela foi analisada apenas no que tange à constitucionalidade e à juridicidade da Convençãointernacional, estando ainda sujeita à apreciação do Plenário da Câmara.

Interessante transcrever o voto do relator da última Comissão, o Deputado Ricardo Berzoini (PT/SP), apresentado em 20/10/2011, em favor da constitucionalidadee juridicidade da Mensagem n ${ }^{\circ}$ 59/2008 do Poder Executivo, ressaltando que a ratificação da Convenção no 158 da OIT acabaria servindo como estímulo para que o legislador interno regulamentasse o art. $7^{\circ}$, I, da CR/88:

[...] fica evidenciado que a ratificação da Convenção no 158 da OIT não impede, em momento algum, a edição de lei complementar, tampouco tem por objeto tornar obrigatória a reintegração/estabilidade no emprego. Não seria crível acreditar que a intenção da OIT fosse a de regulamentar a proteção do emprego de forma minuciosa, exaustiva e impositiva, tendo em vista a quantidade de países membros da Organização e as particularidades dos ordenamentos jurídicos de cada um deles.

Nesse contexto, estando caracterizada a eficácia contida da Convenção n ${ }^{\circ} 158$ da OIT, uma vez que a sua aplicação depende de efetiva integração ao ordenamento jurídico nacional, integração essa que se dará com a aprovação de lei complementar, nos termos do inciso I do art. $7^{\circ}$ da Constituição Federal, tal qual decidido pelo STF, não há que se falar em inconstitucionalidade formal do ato em apreço.[...]

Por fim, e sem entrar no mérito, cabe considerar que a ratificação pode servir como fundamento para que este Poder Legislativo passe a dar a devida importância à discussão sobre a proteção do emprego e, dessa forma, venha a efetivar a edição de lei complementar que defina os conceitos de "despedida arbitrária" e de "sem justa causa", as formas de indenização para as despedidas imotivadas e os outros direitos pertinentes, tal qual estabelecido no inciso I do art. $7^{\circ}$ da Constituição Federal. E, nesse sentido, a Convenção $\mathrm{n}^{\circ} 158$ da OIT pode servir como parâmetro para os debates (BRASIL, 2014a).

\footnotetext{
${ }^{16}$ A Comissão de Relações Exteriores e de Defesa Nacional, em 03/06/2008, decidiu, por maioria, pela rejeição da proposta, fundamentada no "enorme prejuízo para os trabalhadores, para a geração de empregos, para o crescimento interno e a competitividade internacional do país” e pelo fato de que, no texto da Convenção, estaria "claro que esta não se aplica quando se chocar com as leis nacionais (artigo $1^{\circ}$ ) e, no caso do Brasil, isso ocorre com a própria Constituição Federal” (BRASIL, 2014a).

17 Também a Comissão de Trabalho, de Administração e Serviço Público, por maioria, em 11/07/2011, opinou pela rejeição sob a justificativa de que, se a Convenção fosse aprovada, representaria um retrocesso ao país ante o risco iminente de uma redução na criação de empregos e, também, pelo fato de que o Brasil já possui um marco legal protetivo mais do que suficiente contra a dispensa de trabalhadores, fundado no aviso prévio, no Fundo de Garantia por Tempo de Serviço, na indenização sobre o FGTS e no seguro-desemprego (BRASIL, 2014a).
} 
Afinal de contas, nos termos do art. 10 da Convenção, os Estados-Partes não estão obrigados a instituírem em seus ordenamentos a reintegração no emprego, podendo optar pela solução normativa que se revelar mais consentânea e compatível com a legislação e a prática nacionais, o que nos faz crer que poderia haver uma compatibilização entre o texto desta norma, o texto do art. $7^{\circ}$, I, da CR/88 e a realidade brasileira, com o escopo de dar efetividade ao direito fundamental à garantia de emprego.

\section{REPERCUSSÕES DA FALTA DE REGULAMENTAÇÃO DO DIREITO À GARANTIA DE EMPREGO: PERSPECTIVA OBREIRA, PATRONAL E GOVERNAMENTAL}

O trabalho, conforme buscou-se demonstrar, exerce um papel de centralidade na sociedade, o que demonstra sua importância majorada.

Por este motivo ele passou a ser o objeto de um ramo especial do Direito, que, a partir do princípio da proteção, foi estruturado com normas que regulam a relação empregatícia, buscando evitar os malefícios outrora experimentados, quando se concebia a igualdade formal entre empregado e empregador.

Para que a condição social do obreiro seja melhorada através do trabalho prestado à luz do Direito do Trabalho é importante que ele se insira na dinâmica empresarial de forma duradoura e não por prazo certo.

Entretanto, o que se vê hoje é uma grande facilidade de dispensar o trabalhador, sem qualquer justificativa, sendo alta a rotatividade de mão-de-obra no Brasil.

De acordo com pesquisa do DIEESE (DEPARTAMETNO, 2013), por muitos anos, em especial na década de 1990, a maioria da população brasileira não colheu os frutos do crescimento econômico do país, que foi gozado por poucos, gerando enorme concentração de renda, sofrendo os obreiros com as crises econômicas e redução do nível de emprego.

A partir de 2004, houve uma retomada do crescimento econômico e uma melhora da taxa média de desemprego, o que influenciou nos processos de negociação coletiva com ganhos para os trabalhadores.

Entretanto, a alta taxa de rotatividade de mão-de-obra compromete o gozo destes benefícios, que acabam sendo anulados pelas empresas à medida que os empregados são dispensados e outros contratados por salários mais baixos ou pelo piso da categoria. 
Segundo a pesquisa:

O mercado de trabalho é bastante flexível em termos quantitativos. Um nível mínimo de rotatividade é aceitável em qualquer mercado de trabalho. No Brasil, contudo, as taxas de rotatividade da mão-de-obra nos últimos 10 anos se mantiveram em patamares elevados, acima de $40 \%$ praticamente em todo o período.

Em 2007, 14,3 milhões de trabalhadores foram admitidos e 12,7 milhões foram desligados das empresas. Do total de empregados desligados, 59,4\%, ou 7,6 milhões foram dispensados por meio de demissões sem justa causa ou imotivada.

A facilidade para demitir trabalhadores permite que as empresas utilizem esse mecanismo de rotatividade para reduzir os custos salariais, desligando profissionais que recebem maiores salários e contratando outros por menores salários. Os salários dos trabalhadores admitidos no triênio 2005-2007 foram sempre inferiores aos dos trabalhadores desligados (nem todos por justa causa). Os percentuais de redução foram 11,42\%, em 2005, 11,06\%, em 2006, e 9,15\%, em 2007. Ou seja, no momento da contratação, os novos trabalhadores são, na maior parte, contratados com salários menores, o que implica redução gradual do salário médio (DEPARTAMENTO, 2013, p.5).

A ausência de garantia de emprego, sob a perspectiva obreira, acaba sendo fonte de redução de salário e, consequentemente, de seu poder aquisitivo, o que reflete na qualidade de vida, saúde, educação e lazer do trabalhador e sua família.

Ela ainda inibe a busca do empregado por seus direitos no curso da relação de emprego. O que se percebe é que o Direito do Trabalho "tem um baixo índice de cumprimento espontâneo pelos destinatários de seus comandos normativos, muito menor do que qualquer ordenamento admite como tolerável” (PIMENTA, 2004, p.340), havendo no Brasil uma verdadeira síndrome do descumprimento das obrigações. Dentre as causas para esta situação, podemos citar:

[...] a impunidade, absoluta ou relativa, de que gozam as empresas e os empresários de nosso país - é quase sempre mais vantajoso descumprir a lei trabalhista do que cumpri-la espontaneamente, ao mesmo tempo em que é também vantajoso aguardar que os trabalhadores lesados (na verdade, apenas parte deles) recorram ao Judiciário trabalhista para eventuais transações (sempre mais vantajosas, para o devedor, que o total cumprimento das normas trabalhistas) ou para condenações quase sempre tardiamente executadas (PIMENTA, 2000, p.191).

Diante do descumprimento voluntário, reiterado e inescusável da norma pelo destinatário- o empregador -, o titular do direito- o empregado - muitas vezes conformasepura e simplesmente com a ofensa, gerando um fenômeno denominadode litigiosidade contida $^{18}$, para o qual contribui diretamente a falta de regulamentação do art. $7^{\circ}$, inciso I, da

\footnotetext{
${ }^{18}$ O fenômeno da litigiosidade contida é abordado por José Roberto Freire Pimenta (2000), mas segundo o autor, este grave estado de coisas foi analisado pioneiramente na doutrina brasileira por Antônio Álvares da Silva, em seu trabalho "A desjuridicização dos conflitos trabalhistas e o futuro da Justiça do Trabalho no Brasil”, na obra coordenada por Sálvio de Figueiredo Teixeira, "As garantias do cidadão na Justiça”, publicada pela Editora Saraiva, em 1993.
} 
CR/88, tendo em vista o temor por parte do trabalhador em exercer o seu direito de ação no curso da relação de emprego e, por este motivo, ser dispensado injustamente ${ }^{19}$.

Além disso, o obreiro imotivadamente dispensado não tem a possibilidade de saber a causa que gerou o seu desligamento e, consequentemente, de se adequar aos padrões de qualidade exigidos pelo concorrente mercado de trabalho. Também, não há contraditório, carecendo o trabalhador da oportunidade de trazer seus argumentos para evitar a ruptura contratual, tendo de se conformar e se consolar com a multa dos $40 \%$ (quarenta por cento) sobre o FGTS.

Sob a perspectiva empresarial, se a alta rotatividade, por um lado, pode ser instrumento de redução salarial, por outro, ela acaba implicando na majoração de custos com seleção, contratação, treinamento e dispensa de funcionários.

As despesas com treinamento, em especial, são diuturnamente mais expressivas em face do cenário atual de política nacional de combate e prevenção dos acidentes do trabalho. Os deletérios efeitos gerados pelos infortúnios laborais, que fazem com que um trabalhador perca sua vida a cada 3,5 (três vírgula cinco) horas de trabalho (OLIVEIRA, 2011), tem sido veementemente combatidos pelas três esferas do Poder e pela sociedade civil como um todo, sendo exigido da empresa um cuidado cada vez maior com a saúde e segurança do obreiro.

Relevante ressaltar, ainda, que uma das formas de se alcançar melhores resultados dentro da empresa é através da meritocracia, sendo o trabalho mensurado pelo resultado e o obreiro beneficiado em virtude do êxito alcançado.

Essa importante ferramenta de gestão de pessoas está diretamente ligada ao tempo que o trabalhador fica inserido na dinâmica empresarial, pois, quanto mais ele se dedica e aprimora seu trabalho, mais é reconhecido e mais a empresa lucra. A permanência do empregado gera o maior conhecimento e domínio sobre o trabalho realizado e faz com que a empresa invista na sua qualificação, tudo contribuindo para o aumento da produtividade.

Assim, para a empresa é melhor investir no seu funcionário e não praticar uma política de constantes dispensas imotivadas, o que, inclusive, gera mal estar entre os empregados e reflete no seu desempenho. A regulamentação do art. $7^{\circ}$, I, da $\mathrm{CR} / 88$, pode contribuir para esta dinâmica.

No que tange ao argumento de que a garantia de emprego aumentaria os índices de informalidade das relações de emprego, chamamos a atenção para a sua fragilidade. Não raro,

\footnotetext{
${ }^{19}$ Mesmo quando já cessado o vínculo empregatício, o receio é de não conseguir outra colocação profissional, por ter seu nome incluído em "listas negras" que circulam entre empregadores identificando os obreiros que já demandaram na Justiça do Trabalho. Neste sentido, Márcio Túlio Viana (2008).
} 
o destinatário da norma encontra formas de se furtar ao seu cumprimento quando ela lhe causa maiores ônus.

Entretanto, este é um problema decorrente da nossa recente história democrática, haja vista muitos ainda negligenciarem o fato de que a lei é resultado do anseio de diferentes estratos sociais. De tal modo que, assim como o outro deve respeitar a norma que nos beneficia, embora lhe seja onerosa, também nós devemos respeitar a lei de que desgostamos, porque escolhemos viver em um Estado de Democrático de Direito, que abriga interesses antagônicos mas que convivem lado a lado.

Por fim, a alta rotatividade também gera custos para o governo, que perde com o pagamento do seguro desemprego. Estes valores desembolsados poderiam ser investidos em outros programas em benefício dos trabalhadores e empregadores, como, por exemplo, em qualificação de mão-de-obra.

A regulamentação do direito à garantia de emprego, sendo analisada não apenas pelo enfoque obreiro, baseado no princípio da proteção, mas pelo enfoque patronal e governamental, nos faz crer que ela é capaz de gerar expressivos benefícios. Deve ser feita uma análise do tema divorciada de preconceitos e com base em estatísticas e dados comprovados sobre o contexto atual do mercado de trabalho brasileiro, com participação de todos os envolvidos, para se chegar a um texto de lei que reflita a realidade. Assim,

\begin{abstract}
Regulamentar a garantia contra a dispensa imotivada ou arbitrária implica uma tentativa de buscar equilíbrio entre um sistema rígido, que impede qualquer tipo de dispensa, exceto a da "justa causa", e um sistema, como o brasileiro, que garante ampla liberdade do empregador na demissão do empregado. É razoável reconhecer a possibilidade de dispensa em algumas situações, mesmo na ausência de "justa causa”. Todavia, não se pode esquecer o sentido social da proteção e segurança do emprego, a menos que se queira relegá-lo ao mero jogo das forças econômicas. Assim, a busca permanente de equilíbrio entre a segurança no emprego e a liberdade de dispensa dos trabalhadores deve ser assumida como um objetivo da sociedade brasileira (DEPARTAMENTO, 2013, p.9).
\end{abstract}

\title{
7 CONCLUSÃO
}

Desde os tempos mais antigos, o embate de interesses é inerente à relação entre capital e trabalho, mas é preciso absorver os anseios e valores da época em que vivemos, em especial, aqueles que norteiam nosso ordenamento jurídico.

A garantia de emprego, direito fundamental constitucionalmente garantido aos trabalhadores, é instrumento de reafirmação da centralidade do trabalho na sociedade, na medida em que não se trata de inibir a atividade empresarial mas, ao contrário, de adotar 
parâmetros para que ela ocorra, respeitando e promovendoos princípios da dignidade da pessoa humana e a função social do trabalho.

O fundamento da necessidade de regulamentação do referido direito pode ser encontrado nestes princípios constitucionais, bem como nos princípios da proteção e da continuidade da relação de emprego, específicos da seara laboral.

A inserção do direito à garantia de emprego na CR/88 representou um avanço para a classe de trabalhadores, mas a sua falta de regulamentação lhes custa caro, pelo seu temor da dispensa imotivada, pela alta rotatividade da mão-de-obra como instrumento de redução de salário, pelo desconhecimento do motivo de seu desligamento e pela negação da possibilidade de argumentar.

Por vários momentos, vimos o assunto nascer e ser combatido, em especial, quando da ratificação e denúncia da Convenção nº 158 da OIT, o que, por si só, demonstra sua importância.

É preciso analisar o tema sem a paixão que suscita e, de maneira racional, fazer uma analise aprofundada do mercado de trabalho, dos custos da dispensa e da melhor forma de regulamentação da norma, atendendo, dentro do possível, às reivindicações de ambas as partes.

Vivemos em uma era em que a luta não é mais pela criação de leis, mas sim pela manutenção, regulamentação e efetivação dos direitos, para que os preceitos normativos não passem de "promessas não cumpridas”, em especial, na seara laboral, para que as normas trabalhistas possam, de fato, melhorar a condição social do obreiro.

\section{REFERÊNCIAS BIBLIOGRÁFICAS}

BARROS, Alice Monteiro. Curso de Direito do Trabalho. 5.ed. São Paulo: LTR, 2009.

BRASIL. Câmara dos Deputados. Mensagem nº 59/2008. Disponível em: $<$ http://www.camara.gov.br/proposicoesWeb/fichadetramitacao?idProposicao=383867> . Acesso em: 15/01/2014a.

Disponível Supremo Tribunal Federal. Acompanhamento processual ADIn nº 1480/DF. em: $<$ http://www.stf.jus.br/portal/peticaoInicial/verPeticaoInicial.asp?base=ADIN\&s1=Conve n\%E7\%E3o\%20\%20e\%20158\%20e\%20OIT\&processo=1480>. Acesso em: 15/01/2014b. 
Disponível em:

. Supremo Tribunal Federal. Acompanhamento processual ADIn nº 1625/DF.

<http://www.stf.jus.br/portal/peticaoInicial/verPeticaoInicial.asp?base=ADIN\&s1=Conven\%

E7\%E3o\%20\%20e\%20158\%20e\%20OIT\&processo=1625>. Acesso em: 15/01/2014c.

COMPARATO, Fábio Konder. Afirmação histórica dos direitos humanos. 2.ed., rev. e ampl. São Paulo: Saraiva, 2001.

DELGADO, Maurício Godinho. Princípios constitucionais da dignidade da pessoa humana e da proporcionalidade. Síntese Trabalhista, Porto Alegre: Síntese, v. 16, n. 186, p. 5-20, dez. 2004.

. Curso de direito do trabalho. 8.ed. São Paulo: LTr, 2009.

DEPARTAMENTO INTERSINDICAL DE ESTATÍSTICA E ESTUDOS

SOCIOECONÔMICOS. Nota técnica número 61 de março de 2008. A convenção 158 da OIT e a garantia contra a dispensa imotivada. Disponível em:

$<$ http://www.vigilantecntv.org.br/Dieese/nota\%20tecnica\%2061\%20-

\%20RatificacaoConvencao158rev.pdf>. Acesso em: 20/06/2013.

GARCIA, Gustavo Filipe Barbosa. Curso de Direito Processual do Trabalho. 6.ed. Rio de Janeiro: Forense, 2012.

LEDUR, José Felipe. A realização do direito ao trabalho. Porto Alegre: Sergio Antonio Fabris, 1998.

MACIEL, Jose Alberto Couto. Comentários à convenção 158 da OIT. 2.ed, atual. São Paulo; LTR, 1996.

MAGALHÃES, José Luiz Quadros de. Direitos humanos: sua história, sua garantia e a questão da indivisibilidade. São Paulo: J. de Oliveira, 2000.

MARÇAL, Antonio Cota. Princípio: estatuto, função e usos no direito. In: TAVARES, Fernando Horta (coord.). Constituição, Direito e Processo: Princípios Constitucionais do Processo. Curitiba: Editora Juruá. 2007.

OLIVEIRA, Sebastião Geraldo de. Indenização por acidente do trabalho ou doença ocupacional. 6.ed. São Paulo: LTr, 2011.

PIMENTA, José Roberto Freire. Tutelas de Urgência no Processo do Trabalho: o potencial transformador das relações trabalhistas das reformas do CPC brasileiro. In; ., et al., (Coord.). Direito do Trabalho: evolução, crise, perspectivas. São

Paulo: LTr. 2004.

. Aspectos processuais da luta contra a discriminação, na esfera trabalhista:

a tutela antecipatória como mecanismo igualizador dos litigantes trabalhistas. In:

VIANA, Márcio Túlio; RENAULT, Luiz Otávio Linhares. Discriminação. São Paulo: LTr, 2000. 
PLÁ RODRIGUEZ, Américo. Princípios de Direito do Trabalho. 3.ed. atual. São Paulo: LTr, 2000.

SÜSSEKIND, Arnadoet al. Instituições de Direito do Trabalho. São Paulo: LTr, 2005.

VASCONCELOS, Andréa. Dispensa imotivada. Análise à luz da Convenção 158 da OIT. Florianópolis: Conselho Editorial, 2010.

VIANA, Márcio Túlio. Os paradoxos da prescrição: quando o trabalhador se faz cúmplice involuntário da perda de seus direitos. Revista do Tribunal Regional do Trabalho da $3^{a}$ Região, Belo Horizonte, v.47, n.77, p.163-172, jan./jun.2008.

VILLELA, Fábio Goulart. Manual de Direito do Trabalho. Disponível em: http://books.google.com.br/books?id=KKzVU93z5WkC\&dq=. Acesso e: 02/12/2013. 